\title{
Correlation of quantitative changes of gastric mucosal glycoproteins with asprin-induced gastric damage in rats
}

\author{
Y AZUUMI, S OHARA, K ISHIHARA, H OKABE, AND K HOTTA* \\ From the School of Medicine, Kitasato University, Sagamihara, Japan
}

SUMMARY Quantitative changes of gastric mucosal glycoproteins with the gastric damage induced by acetylsalicylic acid (aspirin) in rat have been studied. Gastric injury was easily observed macroscopically within one hour after the oral administration of aspirin. The most striking changes occurred at five hours, and the injury was overcome within nine hours after dosing. The glycoproteins extracted from rat stomach with Tris buffer containing Triton X-100 were fractionated on Bio-Gel A-1.5 m column chromatography and divided into three fractions. The first peak, corresponding to gastric mucus macromolecular neutral and acidic glycoproteins with or without sulphate (Fr.I), was diminished after aspirin administration. A considerable alteration of Fr.I (49\% of control) appeared at three hours, and a gradual return to the control value was observed subsequently. The changes in the amount of the glycoproteins were detected before the macroscopical changes of the mucosa. These results suggest that gastric ulceration induced by aspirin may be caused by a deficiency of gastric mucus macromolecular glycoproteins of gastric mucus.

Histochemical and biochemical studies indicate that neutral glycoproteins and acidic glycoproteins with or without sulphate are present in gastric mucosa. ${ }^{1-3}$ Gastric mucus glycoproteins have well-defined features, distinct from polysaccharide-protein complexes of connective tissue origin. ${ }^{4-8}$ Although the mucus glycoproteins are believed to play an important part in the defense against ulceration, details of their physiological action are not well understood. ${ }^{910}$

The following experiments were carried out to investigate the correlation of quantitative changes of gastric mucus glycoproteins with gastric damage. Gastric damage was induced by acetylsalicylic acid (aspirin) in rat, and gastric mucus macromolecular glycoproteins ${ }^{112}$ were isolated by gel filtration and determined on a quantitative basis.

\section{Methods}

White male Wistar rats weighing approximately $160 \mathrm{~g}$ were used in this work. The animals were fasted for 24 hours before experiment but were

*Address for correspondence: Dr Kyoko Hotta, Department of Biochemistry, School of Medicine, Sagamihara, Kanagawa, Japan.

Received for publication 30 November 1979 permitted free access to water. Aspirin was suspended in $0.5 \%$ carboxymethyl cellulose at a concentration of $50 \mathrm{mg}$ per $\mathrm{ml}$. The aspirin suspension was administered orally as a single dose of $300 \mathrm{mg}$ per $\mathrm{kg}$ body weight, and the animals were killed by exsanguination from the carotid artery at time intervals of one, two, three, five, seven, and nine hours after dosing. The stomachs were excised immediately and cut along the greater curvature. The stomach contents were washed with phosphate buffered saline, and the surface of the mucosa was wiped with soft tissue paper. In order to assess the mucosal damage macroscopical observation was carried out. ${ }^{13}$ Control rats were treated as described above except for the administration of aspirin.

Portions of the glandular stomach were selected macroscopically and excised, and the tissues were lyophilised. The lyophilised three or four stomachs were pooled, weighed, and ground in a mortar. The resultant powder was suspended in 0.05 M Tris- $\mathrm{HCl}$ buffer, $\mathrm{pH} 7 \cdot 2$, containing $2 \%$ Triton X-100 $(1.5 \mathrm{ml} / 100 \mathrm{mg}$ dry tissue) and homogenised by hand in a Potter-Elvehjem glass homogeniser. After incubation at $37^{\circ} \mathrm{C}$ for one hour, the homogenate was centrifuged at $8000 \times g$ at $0^{\circ} \mathrm{C}$ for 30 minutes. The extraction of the precipitate was repeated three times. The pooled supernatant was used 
for additional experiment. Two millilitres of the supernatant were applied to Bio-Gel A-1.5 m column $1 \times 90 \mathrm{~cm}$, which had been pre-equilibrated with Tris-HC1 buffer containing Triton as described above, and the column was eluted with this buffer. Two millilitre fractions were collected, and their hexose and protein were determined. The elution pattern of one of the extracts from control rat stomach on Bio-Gel A-1.5 m is shown in the Figure. The eluted materials were divided into three fractions as indicated in the Figure (Fr. I, Fr. II, and Fr. III). The corresponding eluates were pooled. Hexose was analysed by the phenol-sulphuric acid method ${ }^{14}$ using galactose as a standard. To calculate hexose concentration in each sample, results were converted to milligram per gram of dry tissue. Protein content was measured using the Bio-Rad protein assay kit. ${ }^{15}$ Before protein assay Triton $\mathrm{X}-100$ was removed from samples according to the method of Holloway. ${ }^{16}$ The radial diffusion assay ${ }^{17} 18$ was used to measure the peptic activity in the material eluted from Bio-Gel A-1.5 m column. Digestion by chondroitinase ABC was carried out according to the method described by Yamagata et al..$^{19}$ using chondroitin 4-sulphate as a standard.

\section{Results}

A quantitative assessment of gastric damage produced by aspirin, as measured by the number of

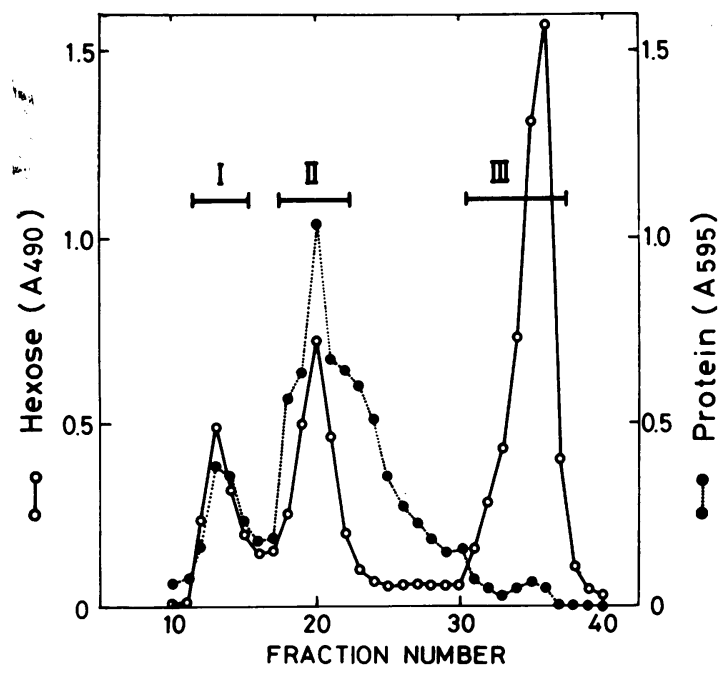

Figure Bio-Gel A-1.5 m column chromatography (see text) of the extract from control rat stomach. Samples were analysed by the phenol-sulphuric acid method measured at $A_{490}(\bigcirc-\bigcirc)$ and by the Bio-Rad protein assay measured at $A_{595}\left(O_{---O}\right)$. The solid bars (I, II, and III) indicate the fractions which were pocled. erosions and their size, and the number of animals with lesions present, is shown in Table 1. No macroscopical damage was observed in the forestomach. Haemorrhagic erosions and linear ulcers in the glandular stomach were visible in six of the 23 experimental stomachs within one hour after aspirin administration. The extent of damage was increased with the passage of time. The most striking changes occurred five hours after dosing. A gradual return to the control situation was observed later. The injury had nearly abated macroscopically within nine hours.

The wet weight of whole stomach per rat was unchanged with or without aspirin treatment $(600 \pm 20 \mathrm{mg})$. The weight ratio of glandular stomach to forestomach was about $3: 1$. The average weight of dried glandular stomach per rat was also compared with the aspirin treated and control rats. No dif-

Table 1 Degree of gastric mucosal damage produced by aspirin

\begin{tabular}{|c|c|c|c|c|}
\hline $\begin{array}{l}\text { Time after } \\
\text { dosing }(h)\end{array}$ & $\begin{array}{l}\text { Rats } \\
\text { (no.) }\end{array}$ & $\begin{array}{l}\text { Mucosal lesions" } \\
\text { (gross findings) }\end{array}$ & Ulcer index $\dagger$ & $\begin{array}{l}\text { Percent } \\
\text { incidence }\end{array}$ \\
\hline Control & 38 & $\begin{array}{cl}\text { Gr. } 0 & 38(100 \%) \\
1 & 0(0) \\
2 & 0(0) \\
3 & 0(0) \\
4 & 0(0)\end{array}$ & 0 & 0 \\
\hline 1 & 23 & $\begin{array}{rl}\text { Gr. } 0 & 17(73.9) \\
1 & 4(17 \cdot 4) \\
2 & 2(8 \cdot 7) \\
3 & 0(0) \\
4 & 0(0)\end{array}$ & $0 \cdot 35$ & $26 \cdot 1$ \\
\hline 2 & 22 & $\begin{array}{rr}\text { Gr. } 0 & 7(31 \cdot 8) \\
1 & 13(59 \cdot 1) \\
2 & 2(9 \cdot 1) \\
3 & 0(0) \\
4 & 0(0)\end{array}$ & 0.77 & $68 \cdot 2$ \\
\hline 3 & 24 & $\begin{array}{rr}\text { Gr. } 0 & 3(12 \cdot 5) \\
1 & 13(54 \cdot 1) \\
2 & 4(16 \cdot 7) \\
3 & 4(16 \cdot 7) \\
4 & 0(0)\end{array}$ & $1 \cdot 33$ & $87 \cdot 9$ \\
\hline 5 & 24 & $\begin{array}{rl}\text { Gr. } 0 & 0(0) \\
1 & 7(29 \cdot 2) \\
2 & 8(33 \cdot 3) \\
3 & 6(25 \cdot 0) \\
4 & 3(125)\end{array}$ & $2 \cdot 21$ & $100 \cdot 0$ \\
\hline 7 & 12 & $\begin{array}{rl}\text { Gr. } 0 & 7(58 \cdot 3) \\
1 & 3(25 \cdot 0) \\
2 & 2(16 \cdot 7) \\
3 & 0(0) \\
4 & 0(0)\end{array}$ & 0.58 & $41 \cdot 7$ \\
\hline 9 & 20 & $\begin{array}{rl}\text { Gr. } 0 & 16(80.0) \\
1 & 2(10.0) \\
2 & 2(10.0) \\
3 & 0(0) \\
4 & 0(0)\end{array}$ & $0 \cdot 30$ & $20 \cdot 0$ \\
\hline
\end{tabular}

-Severity of gastric mucosal damage was graded as follows: grade $\mathbf{0}$ no lesion; grade 1-haemorrhagic erosion (less than 5); grade 2haemorrhagic erosion (more than 5) or one small ulcer; grade 3many small linear ulcers (shorter than $2 \mathrm{~mm}$ ) or single linear ulcer of marked size (longer than $2 \mathrm{~mm}$ ); grade 4 -multiple linear ulcers of marked size (Adami et al.).

†The ulcer index for each group was calculated by multiplying the number of rats in each grade by the number and dividing by the total number of rats in each group. 
ferences were found (98 to $102 \%$ of control). 50 to $60 \%$ of materials in rat stomach powder were easily solubilised by Tris-HC1 buffer containing Triton X-100. The recovery rate of the hexose content in extract was approximately $70 \%$ of that in stomach powder and was constant in all cases. Carbohydrate-containing materials in the residue extracted three times were unable to solubilise subsequently by the method used above. In order to investigate the contamination of mucopolysaccharides which are components of connective tissue, the extract was digested with chondroitinase ABC. The content of mucopolysaccharides expressed as chondroitin 4-sulphate was less than $0.1 \%$ of the material solubilised by the Triton-buffer. The respective elution patterns of control rats on Bio-Gel A-1.5 m were very similar to the pattern shown in the Figure. The first peak corresponding to neutral and acidic glycoproteins with or without sulphate, which were characterised as mucus glycoproteins, ${ }^{1112}$ was eluted with the void volume. The bulk of proteins with or without carbohydrate involving pepsin, serum proteins, and glycolipids which were extractable with chloroform-methanol (2:1) was eluted in the second peak. Hexose-containing low molecular materials were retarded in the third peak. A distinct change of elution pattern was induced in the first peak of the aspirin-treated rats compared with the controls. A considerable diminution of the first peak expressed as hexose content was observed in the three hour sample after aspirin dosing. The distribution of hexose contents in three fractions (Fr. I, II, and III) separated by gel filtration is shown in Table 2. A statistically significant decrease occurred in Fr. I expressed as hexose content, indicating a lowered content of gastric mucus macromolecular glycoproteins after the administration of aspirin. In the aspirin-treated rats the alteration of each fraction, especially Fr. I, had appeared before the macroscopical change of mucosa. The hexose content of Fr. I remained low during the test period, although the percentage of recovery on total hexose was nearly $100 \%$ at nine hours after dosing.

\section{Discussion}

It is well known that aspirin causes damage to the gastric mucosa, although there is much argument about the mechanism for the development of the gastric damage by aspirin. ${ }^{20-23}$ Little has been reported about the biochemical change of the gastric mucosal components during the course of the damage. Menguy and Masters ${ }^{24}$ observed that the administration of aspirin to rats caused a decrease in gastric mucosal content of mucus measured by periodic acid Schiff staining of sections of gastric mucosa and by direct measurement of gastric mucosal content of hexosamine and fucose. Kent and Allen $^{25}$ reported that salicylic acid had an inhibitory effect within two to three hours on glycoprotein biosynthesis in scrapings from sheep colonic and human gastric tissues. These facts are assumed to be correlated with the amount of gastric mucosal glycoprotein with gastric damage. It is obvious from the result of our present paper that gastric mucus glycoproteins were diminished in association with gastric damage induced by aspirin. In particular, the quantitative alteration of macromolecular glycoproteins was considerable.

The gastric surface mucosal cells, which are rich in glycoproteins and produce the mucin with concomitant death of the cells, play an important part in protecting the mucosa of the digestive tract from peptic ulceration. ${ }^{26}$ 27 Our preliminary studies indicate that the sulphated glycoproteins isolated from porcine gastric mucosa have apparent peptic inhibitory activity due to the binding of sulphated glycoproteins to the protein substrate of pepsin and protected gastric gland components from peptic digestion. ${ }^{8}$ Most of the ${ }^{35} \mathrm{SO}_{4}{ }^{2-}$ incorporated into rat mucosa were recovered in the first peak on Bio-Gel

Table 2 Distribution of hexose in fractions

\begin{tabular}{|c|c|c|c|c|c|}
\hline \multirow[t]{2}{*}{$\begin{array}{l}\text { Time after } \\
\text { dosing }(h)\end{array}$} & \multirow[t]{2}{*}{ Rats (no.) } & \multicolumn{4}{|l|}{ Hexose value } \\
\hline & & Fraction I & Fraction $I I$ & Fraction III & Total \\
\hline $\begin{array}{l}\text { Control } \\
1 \\
2 \\
3 \\
5 \\
7 \\
9\end{array}$ & $\begin{array}{l}38 \\
23 \\
22 \\
24 \\
24 \\
12 \\
20\end{array}$ & $\begin{array}{l}4 \cdot 55 \pm 0.40 *(100) \dagger \\
3.07 \pm 0.96(67) \\
2 \cdot 72 \pm 0.66(60) \\
2 \cdot 25 \pm 0.32(49) \\
2 \cdot 66 \pm 0.29(58) \\
3.32 \pm 0.77(73) \\
3.55 \pm 0.15(78)\end{array}$ & $\begin{array}{l}7.08 \pm 1.94(100) \\
6.03 \pm 0.32(85) \\
5.51 \pm 0.44(78) \\
5.90 \pm 0.44(83) \\
5.46 \pm 0.44(77) \\
5.70 \pm 0.55(81) \\
6.64 \pm 0.64(94)\end{array}$ & $\begin{array}{c}11.63 \pm 1.64(100) \\
9.51 \pm 3.16(82) \\
9.43 \pm 0.72(81) \\
11.40 \pm 1.52(98) \\
13.09 \pm 0.65(113) \\
13.11 \pm 0.88(113) \\
12.88 \pm 0.26(110)\end{array}$ & $\begin{array}{l}23.26 \pm 3.49(100) \\
18.61 \pm 2.15(80) \\
17.66 \pm 1.80(76) \\
19.55 \pm 1.87(84) \\
21.21 \pm 1.19(91) \\
22.13 \pm 0.58(95) \\
23.07 \pm 0.83(99)\end{array}$ \\
\hline
\end{tabular}

"Hexose value is shown as average concentration in $\mathrm{mg}$ hexose per gram of dry tissue and expressed as mean \pm SD. †Expressed as percent of control. 
A-1.5 m chromatography as mucus sulphated glycoproteins ${ }^{12}$ and, moreover, the first peak corresponded to gastric mucus glycoproteins, ${ }^{11}$ which were similar to the human and porcine gastric mucus glycoproteins described previously. ${ }^{588}$ The isolated macromolecular glycoproteins with or without sulphate were resistant to proteolysis. ${ }^{78}$ These observations would imply that the mucus macromolecular glycoproteins fractionated by gel filtration (Fr. I, Figure) confer a protective function on the gastric mucosa. The changes of the amount of the glycoproteins observed in this work are particularly interesting when considering the possible physiological role of the mucus glycoproteins in gastric mucosa. A positive correlation between the amount of protective glycoproteins and gastric damage may be important with respect to the possible role of glycoproteins in the defense against ulceration. There is little doubt that the decreased mucus glycoprotein in mucosa would have a harmful effect on the protection of mucosa from peptic digestion.

This work was supported in part by grants from the Japanese Ministry of Education.

\section{References}

${ }^{1}$ Buddecke E. Glycoproteins in mammals. In: Gottschalk A, ed. Glycoproteins, BBA library, Vol 5, 2nd ed. Amsterdam: Elsevier, 1978: 535-8.

${ }^{2}$ Walsh JH. Control of gastric secretion. In: Sleisenger $\mathrm{MH}$, Fordtran JS, ed. Gastrointestinal disease. Philadelphia: Saunders WB, 1973: 144-62.

${ }^{3}$ Sheahan DG, Jervis HR. Comparative histochemistry of gastrointestinal mucosubstances. Am J Anat 1976; 146: 103-32.

${ }^{4}$ Schrager J. The composition and some structural features of the principal gastric glycoprotein. Digestion 1969; 2: 73-89.

${ }^{5}$ Schrager J, Oates MDG. A comparative study of the major glycoprotein isolated from normal and neoplastic gastric mucosa. Gut 1973; 14: 324-9.

${ }^{6}$ Schrager J, Oates MDG. The isolation and partial characterization of a glycoprotein isolated from human gastric aspirates and from extracts of gastric mucosae. Biochim Biophys Acta 1974; 372: 183-95.

${ }^{7}$ Hotta K, Goso K. Isolation and partial characterization of gastric juice sulphated glycoproteins. IXth International Symposium on Carbohydrate Chemistry Abstract. London: 1978: 407-8.

${ }^{8}$ Takagaki YM, Hotta K. Characterization of peptic inhibitory activity associated with sulfated glycoprotein isolated from gastric mucosa. Biochim Biophys Acta 1979; 584: 288-97.

'Glass GBJ. Current status of the 'glandular mucoprotein' and 'mucoproteose' fractions of the gastric mucin: A review of 15 years' progress in this area. Ann NY Acad Sci 1967; 140: 804-34.

${ }^{10}$ Horowitz MI. Gastrointestinal glycoproteins. In: Horowitz MI, Pigman W, eds. The glycoconjugates, Vol 1. New York: Academic Press, 1977: 189-213. ${ }^{11}$ Ishihara K, Ohara S, Yoshida K, Azuumi Y, Hotta K. Isolation and partial characterization of rat gastric mucus glycoproteins Seikagaku 1979; 51: 611 .

${ }^{12}$ Ohara S, Ishihara K, Goso K, Hotta K, Azuumi Y, Okabe $\mathrm{H}$. Incorporation of ${ }^{35} \mathrm{SO}_{4}{ }^{2-}$ into sulfated glycoprotein of gastric mucosa maintained in organ culture of rat gastric slices. Jpn J Gastroenterol 1979; 76: 593.

${ }^{13}$ Adami E, Marazzi-Uberti E, Turba C. Pharmacological research on gefarnate, a new synthetic isoprenoid with an antiulcer action. Arch Int Pharmacodyn Ther 1964; 147: 113-45.

${ }^{14}$ Dubois M, Gilles KA, Hamilton JK, Robers PA, Smith F. Colorimetric methods for determination of sugar and related substances. Anal Chem 1956; 28: $350-6$.

${ }^{15}$ Bradford MM. A rapid and sensitive method for the quantitation of microgram quantities of protein utilizing the principle of protein-dye binding. Anal Biochem 1976; 72: 248-54.

${ }^{16}$ Holloway PW. A simple procedure for removal of Triton X-100 from protein samples. Anal Biochem 1973; 53: 304-8.

${ }^{17}$ Doleschel W, Auerswald W. Gel diffusion method for determination of pepsin. Clin Chim Acta 1973; 49: 105-8.

${ }^{18}$ Ishida H, Hotta K, Tamechica Y, Okabe H. An investigation of the measurement of gastric pepsin. (Japanese.) Jpn J Gastroenterol 1977; 74: 924-30.

${ }^{19}$ Yamagata T, Saito H, Habuchi O, Suzuki S. Purification and properties of bacterial chondroitinases and chondrosulfatases. $J$ Biol Chem 1968; 243: 1523-35.

${ }^{20}$ Smith MJH. Toxicology. In: Smith MJH, Smith PK, eds. The salicylates a critical bibliographic review. New York: Wiley Interscience, 1966: 233-306.

${ }^{21}$ Salter RH. Aspirin and gastrointestinal bleeding. Am J Dig Dis 1968; 13: 38-58.

${ }^{22}$ Cooke AR. Drugs and peptic ulceration. In: Sleisenger MH, Fordtran JS, eds. Gastrointestinal disease. Philadelphia: W B Saunders, 1973: 642-56.

${ }^{23}$ Rainsford KD. Electronmicroscopic observations on the effects of orally administered aspirin and aspirinbicarbonate mixtures on the development of gastric mucosal damage in the rat. Gut 1975; 16: 514-27.

${ }^{24}$ Menguy R, Masters YF. Effects of aspirin on gastric mucous secretion. Surg Gynecol Obstet 1965; 120: 92-8.

${ }^{25} \mathrm{Kent}$ PW, Allen A. The biosynthesis of intestinal mucins. Biochem $J$ 1968; 106: 645-58.

${ }^{26}$ Willems $\mathrm{G}$. Cell renewal in the gastric mucosa. Digestion 1972; 6: 46-63.

${ }^{27}$ Terho TT, Hartiala K. Metabolic turnover of sulphated heteroglycans in the gastrointestinal tract, cartilage and skin of the rat. Biochim Biophys Acta 1973; 304: 591-610. 